\title{
Enhanced Instantaneous Power Theory with Average Algorithm for Indirect Current Controlled Three-Level Inverter-Based Shunt Active Power Filter under Dynamic State Conditions
}

\author{
Yap Hoon, Mohd Amran Mohd Radzi, Mohd Khair Hassan, and Nashiren Farzilah Mailah \\ Department of Electrical and Electronic Engineering, Faculty of Engineering, Universiti Putra Malaysia (UPM), \\ 43400 Serdang, Selangor, Malaysia \\ Correspondence should be addressed to Yap Hoon; davidhoon0304@hotmail.com
}

Received 12 October 2015; Accepted 28 February 2016

Academic Editor: Rafael Morales

Copyright (C) 2016 Yap Hoon et al. This is an open access article distributed under the Creative Commons Attribution License, which permits unrestricted use, distribution, and reproduction in any medium, provided the original work is properly cited.

\begin{abstract}
An enhanced harmonics extraction algorithm based on Instantaneous Power (PQ) Theory is proposed for indirect current controlled (ICC) three-level neutral point diode clamped (NPC) inverter-based shunt active power filter (SAPF). SAPF is famous in current harmonics mitigation for its flexibility in dealing with dynamic state conditions. As for its controller, PQ Theory has served the major role in harmonics extraction algorithm due to its simple implementation features. However, it suffers from serious time delay due to its dependency on sluggish numerical filters. Furthermore, the algorithm is mostly designed to suit the operation of direct current controlled (DCC) SAPF which requires the knowledge of actual SAPF current (injection current). This leads to inaccurate mitigation as the injection current does not possess the exact information on actual source current which suffers from switching ripples problems. Therefore, two major modifications are introduced involving the development of mathematical average algorithm to replace numerical filter for fundamental real power computation and the formation of mathematical current relationship to change DCC to ICC based operation. The proposed algorithm is developed and evaluated in MATLAB/Simulink. From the simulation results, significant improvement in terms of Total Harmonic Distortion (THD) and response time is presented in comparison to conventional algorithm.
\end{abstract}

\section{Introduction}

The proliferation of nonlinear loads such as adjustable speed drives, power converters, and switched mode power supplies, as well as other power electronics products has posted significant power quality problems in power distribution system. These problems are commonly related to electrical equipment breakdown caused by voltage, current, or frequency deviations [1]. As one of the most hazardous power quality problems, current harmonics generated by the nonlinear loads cause equipment overheating, voltage quality degradation, excessive transmission power losses, and malfunction of sensitive devices [2,3]. Moreover, they also decrease overall system efficiency and worsen power factor (PF) performances. Therefore, it is crucial to mitigate the harmonics level of a power system. Shunt active power filter (SAPF) [4, 5] is designed specifically for this purpose. Additionally, it also provides reactive power compensation meant for power factor correction.

Most SAPFs utilize a standard two-level inverter configuration in their design. However, multilevel inverters have recently proven to possess significant advantages over conventional two-level inverters $[6,7]$. Their ability to produce stepwise output with higher voltage level reduces the harmonics contents of the output signals and simultaneously minimizes the power losses. However, in the context of APFs, the multilevel inverters employed are mostly restricted to three-level $[8,9]$ due to complexity in controller design which involves larger number of switching states and greater severity of voltage imbalance to the capacitors as the number 
of level increases. In three-level neutral point diode clamped (NPC) inverter, voltage across the split capacitors has to be maintained as half of the overall DC-Bus voltage.

The effectiveness of SAPFs in power quality mitigation strictly depends on their control strategies. Specifically, the controller comprises three main algorithms, namely, harmonics extraction algorithm, voltage control algorithm, and current control or switching algorithm. Among these algorithms, the harmonics extraction algorithm is deemed to be the most crucial part that leads SAPF to achieve its optimal performance $[10,11]$. Accurate and efficient harmonics extraction leads to proper and fast reference current generation which further controls the SAPF to generate the required injection current for harmonics mitigation.

In recent years, various research works on this particular algorithm have been reported in the literature including Synchronous Reference Frame (SRF) [12, 13], Instantaneous Power (PQ) Theory [11, 14-18], DQ-axis with Fourier (DQF) [19], Fast Fourier Transform (FFT) [20], Synchronous Detection (SD) [21, 22], wavelet-based approach [23], and Artificial Neural Network (ANN) $[24,25]$. Among all the existing algorithms, $P Q$ Theory has advantages over the others such as simple design, increased speed, and fewer calculations, making it more likely to be implemented practically.

However, the latest trend in $P Q$ Theory algorithm is still applying numerical filters such as low pass filter (LPF) [14, 16-18], both LPF and high pass filter (HPF) [11], and band reject filter (BRF) [15] to detect the desired real power signal for reference current generation. The dependency on these sluggish numerical filters is the main factor that limits the harmonics extraction performance which in turn degrades the overall harmonics mitigation result. Moreover, the performance of numerical filters strictly depends on their tuned cutoff frequency where the tuning is normally realized through tedious approach. Furthermore, a good trade-off between cutoff frequency and the order of filter is difficult to be attained, but it is required to ensure optimum performance.

Besides that, another weakness of the conventional $P Q$ Theory algorithm is related to the characteristic of its generated reference current. To date, the nonsinusoidal reference current is mainly derived from the extracted current harmonics [11, 14-18] and thus forces the SAPF to operate based on direct current controlled (DCC) scheme [26-28] where the knowledge of actual SAPF injection current is required in generating the desired PWM switching signals to control the switching activities of SAPF for harmonics mitigation.

From the literature $[4,28,29]$, it is revealed that switching activities of SAPF produces ripples in the source current. In the field of harmonics mitigation, it is important to address switching ripples problems as the THD performance of the mitigated source current is degraded. A DCC scheme which operates based on comparison of measured injection current with its nonsinusoidal reference current counterpart does not possess accurate information on the characteristic of the actual source current. Therefore, even if the source current is polluted by switching ripples, the DCC scheme will not be able to mitigate the ripples due to the lack of necessary information.
Although indirect current controlled (ICC) scheme which operates based on the comparison of the actual source current with its sinusoidal reference current counterpart [2629] has been proven to overcome the weakness of DCC scheme, there is still no work on $P Q$ Theory which has been conducted together with ICC scheme. In fact, it is the characteristic of conventional PQ Theory algorithm itself that makes it not suitable to be applied in ICC scheme.

On top of that, the key parameters that determine the performance of SAPF are the THD value, PF, and dynamic response. Basically, the previous literatures [11, 1618 ] reported that SAPF which operates based on $P Q$ Theory successfully performed within the limit (THD < 5\%) set by IEEE Standard 519-2014 [30] with PF close to unity. Meanwhile, the best response time achieved is within $0.05 \mathrm{~s}$ which corresponds to 2.5 cycles of $50 \mathrm{~Hz}$ signal $[11,16]$. However, further improvement can still be done especially in reducing the unnecessary delay resulting from inefficient harmonics extraction algorithm which will surely improve the dynamic performance of SAPF.

Therefore, this paper presents an enhanced version of $P Q$ Theory algorithm known as Enhanced $P Q$ with average algorithm that suits the operation of ICC based SAPF in which the reference current is derived from fundamental active current instead of the current harmonics. Moreover, a mathematical average algorithm is proposed to overcome the drawbacks of the sluggish numerical filters. The design concept and the effectiveness of the proposed algorithm are verified using MATLAB/Simulink. For performance comparison, the conventional $P Q$ Theory algorithm is developed, and both the algorithms are tested under steady and dynamic state conditions.

The rest of the paper is organized as follows. In Section 2, the proposed SAPF with its control strategies is explained. In Section 3, the details of the proposed current harmonics extraction algorithm are presented with clear illustration. In Section 4, simulation results are presented and discussed showing the effectiveness of the proposed algorithm in comparison to the conventional algorithm. The paper ends with a brief conclusion in Section 5 by summarizing the significant contributions of this work.

\section{Proposed SAPF with Control Strategies}

The proposed SAPF connected at point of common coupling (PCC) between three-phase source and nonlinear load and its control strategies are shown in Figures 1 and 2, respectively. A three-phase three-level NPC inverter is employed to function as the SAPF, and the nonlinear load consists of a bridge rectifier which is considered as the worst source of harmonics in electrical system [31, 32].

Meanwhile, the controller is composed of harmonics extraction algorithm, DC-Bus voltage control algorithm, synchronizer algorithm, neutral point voltage control algorithm, and current control (switching) algorithm.

The proposed controller is designed to perform the following functions.

(1) Fundamental Real Power Detection. The source voltage $v_{S}$ and load current $i_{L}$ are sensed to obtain their 


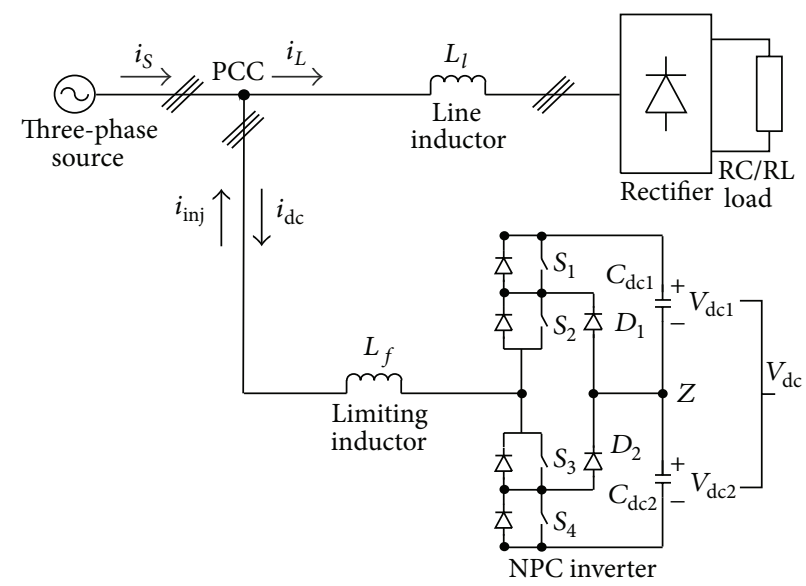

FIgUre 1: The proposed SAPF connected at PCC.

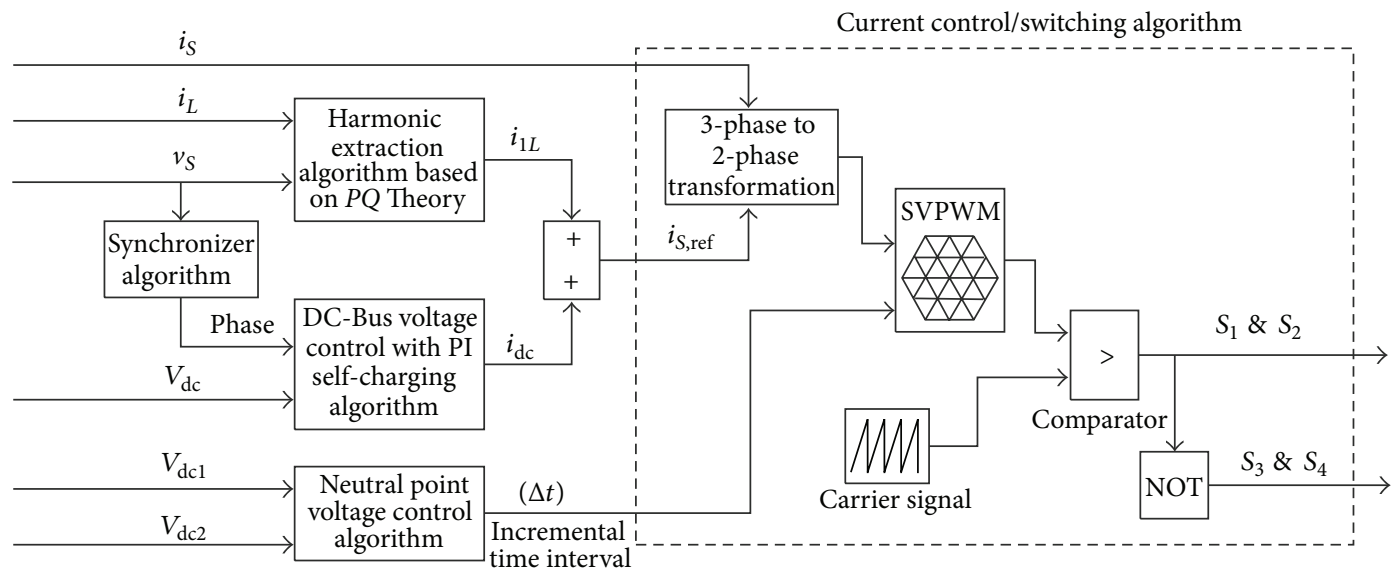

FIGURE 2: The proposed SAPF controller showing the harmonics extraction algorithm and all the other associated algorithms.

corresponding real power $P$. The fundamental component of the calculated real power is then detected and reconverted back to fundamental active current $i_{1 L}$.

(2) DC-Bus Voltage Regulation. Instantaneous DC current $i_{\mathrm{dc}}$ is calculated and drawn by the proposed SAPF to maintain DC-Bus voltages $\left(V_{\mathrm{dc}}, V_{\mathrm{dc} 1}\right.$, and $\left.V_{\mathrm{dc} 2}\right)$ at desired level.

(3) Reference Current Generation. The proposed controller utilizes both $i_{1 L}$ and $i_{\mathrm{dc}}$ to generate the reference source current signal $i_{S \text {, ref }}$.

(4) Minimization of Neutral Point Voltage Deviation. The differences between $V_{\mathrm{dc} 1}$ and $V_{\mathrm{dc} 2}$ are taken to generate an incremental time interval $\Delta t$ which adjusts the time distribution of the switches. This approach ensures equal inflow and outflow of the current at the neutral point $Z$, thus reducing the deviation.

(5) Regulation of Instantaneous Current. The source current $i_{S}$ is regulated through proper switching activities of SAPF controlled by the generated switching signals $S_{1-4}$.

Based on Figure 1, it is clear that the current expression before connecting SAPF can be written as

$$
i_{S}=i_{L}=i_{1 L}+i_{H},
$$

where $i_{H}$ is the current harmonics generated due to nonlinearity characteristic of nonlinear loads. Under the presence of nonlinear loads, the source current $i_{S}$ is polluted by the addition of $i_{H}$ and causes it to displace away from $v_{S}$.

The installation of parallel connected SAPF at PCC as the proposed current harmonics mitigation as well as reactive power compensation strategy has introduced additional signal meant to mitigate the effect of $i_{H}$. The mitigation process is accomplished by injecting the required injection current $i_{\text {inj }}$ to cancel $i_{H}$ during operating state of SAPF and drawing the necessary $i_{\mathrm{dc}}$ to regulate the switching losses during nonoperating state of SAPF. Therefore, the new current expression is now written as

$$
i_{S}=i_{1 L}+i_{H}+i_{\mathrm{dc}}-i_{\text {inj }}
$$




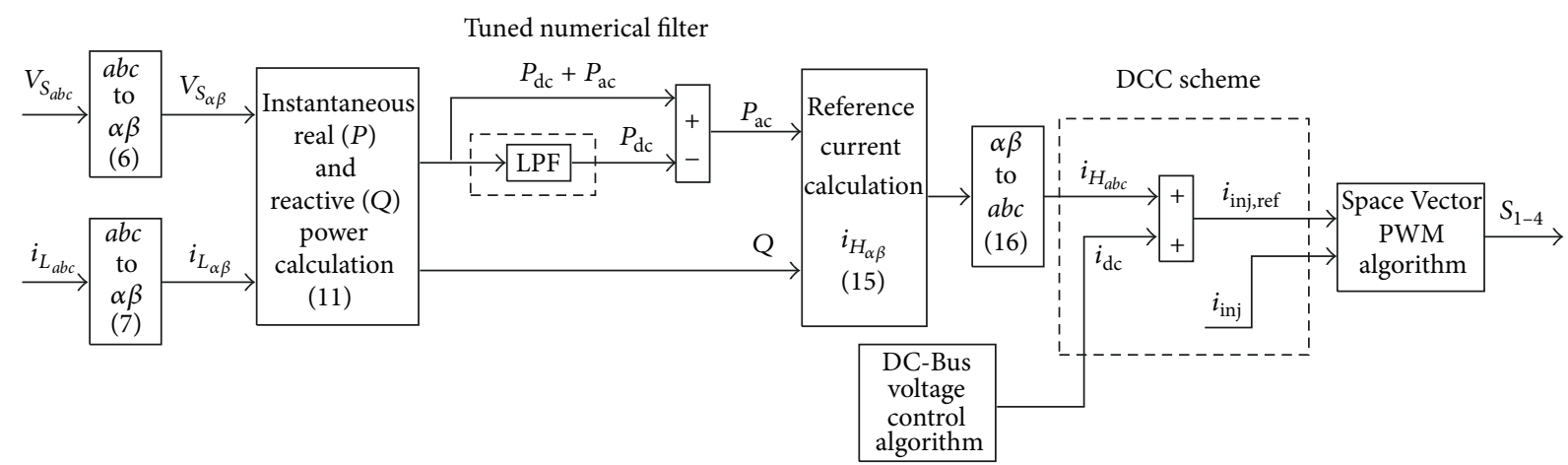

FIGURE 3: The conventional PQ Theory algorithm operating with DCC scheme.

which can be further simplified as

$$
i_{S}=i_{1 L}+i_{\mathrm{dc}}
$$

when $i_{\text {inj }}$ is made equivalent to $i_{H}$.

According to (3), the mitigated $i_{S}$ is presumed to have recovered its pure sinusoidal shape and is in phase with $v_{S}$.

This paper focuses mainly on harmonics extraction algorithm. A synchronizer is utilized to provide sinusoidal referencing signal to the voltage control algorithm governed by self-charging technique $[33,34]$. Meanwhile, the switching control is realized through $25 \mathrm{kHz}$ Space Vector PWM (SVPWM) [8, 35-38] switching algorithm with the help from the neutral point voltage control algorithm [38-40] adjusting the switching time according to the behaviour of the instantaneous DC-Bus voltages.

\section{Proposed Enhanced $P Q$ with Average Algorithm}

In order to provide better understanding of the proposed algorithm and at the same time show proper comparison, the details of the existing algorithm, namely, conventional $P Q$ Theory algorithm, are first presented serving as a benchmark for improvement. Next, with reference to the conventional $P Q$ Theory algorithm, the proposed algorithm known as Enhanced $P Q$ with average algorithm is elaborated highlighting the improvements made.

3.1. Conventional PQ Theory Algorithm. The overall harmonics extraction process flow based on conventional $P Q$ Theory is shown in Figure 3. Basically, the extraction process is realized through a series of mathematical calculations of Instantaneous Power in a balanced three-phase system. The calculations are conducted in $\alpha$ - $\beta$ coordinates where all the threephase signals involved are first translated into $\alpha-\beta$ domain via a mathematical transformation represented by matrix $[M]$ given as

$$
[M]=\sqrt{\frac{2}{3}}\left[\begin{array}{ccc}
\cos \theta_{1}(t) & \cos \theta_{2}(t) & \cos \theta_{3}(t) \\
\sin \theta_{1}(t) & \sin \theta_{2}(t) & \sin \theta_{3}(t)
\end{array}\right],
$$

where

$$
\theta_{\mathrm{ph}}(t)=\theta\left(t-\frac{2 \pi}{3}(\mathrm{ph}-1)\right), \quad \mathrm{ph}=1,2,3
$$

and $\theta(t)$ is an angular arbitrary function representing the phase angle of each signal.

Consequently, the $P Q$ Theory applies this matrix to transform the three-phase voltages and currents into their respective representation in $\alpha$ - $\beta$ coordinates by means of Clarke-transformation [41] which can be expressed as the following matrix relation:

$$
\begin{aligned}
& {\left[\begin{array}{l}
v_{\alpha} \\
v_{\beta}
\end{array}\right]=\sqrt{\frac{2}{3}}\left[\begin{array}{ccc}
1 & -\frac{1}{2} & -\frac{1}{2} \\
0 & \frac{\sqrt{3}}{2} & -\frac{\sqrt{3}}{2}
\end{array}\right]\left[\begin{array}{l}
v_{a} \\
v_{b} \\
v_{c}
\end{array}\right],} \\
& {\left[\begin{array}{l}
i_{\alpha} \\
i_{\beta}
\end{array}\right]=\sqrt{\frac{2}{3}}\left[\begin{array}{ccc}
1 & -\frac{1}{2} & -\frac{1}{2} \\
0 & \frac{\sqrt{3}}{2} & -\frac{\sqrt{3}}{2}
\end{array}\right]\left[\begin{array}{l}
i_{a} \\
i_{b} \\
i_{c}
\end{array}\right],}
\end{aligned}
$$

where $v_{a}, v_{b}$, and $v_{c}$ and $i_{a}, i_{b}$, and $i_{c}$ are the three-phase voltages and currents, respectively.

In $\alpha$ - $\beta$ coordinates, the complex power $S$ can be represented as

$$
\begin{aligned}
S & =P+j Q=v_{\alpha \beta} i_{\alpha \beta}^{*}=\left(v_{\alpha}-j v_{\beta}\right)\left(i_{\alpha}+j i_{\beta}\right) \\
& =\left(v_{\alpha} i_{\alpha}+v_{\beta} i_{\beta}\right)+j\left(v_{\alpha} i_{\beta}-v_{\beta} i_{\alpha}\right),
\end{aligned}
$$

where $P$ and $Q$ represent the instantaneous real and reactive power, respectively, and $*$ represent a complex conjugate.

Hence, the instantaneous real power $P$ is given by

$$
P=\left(v_{\alpha} i_{\alpha}+v_{\beta} i_{\beta}\right) \text {. }
$$
by

Meanwhile, the instantaneous reactive power $Q$ is given

$$
Q=\left(v_{\alpha} i_{\beta}-v_{\beta} i_{\alpha}\right)
$$

Equations (9) and (10) can be rewritten as

$$
\left[\begin{array}{l}
P \\
Q
\end{array}\right]=\left[\begin{array}{cc}
v_{\alpha} & v_{\beta} \\
-v_{\beta} & v_{\alpha}
\end{array}\right]\left[\begin{array}{l}
i_{\alpha} \\
i_{\beta}
\end{array}\right] .
$$




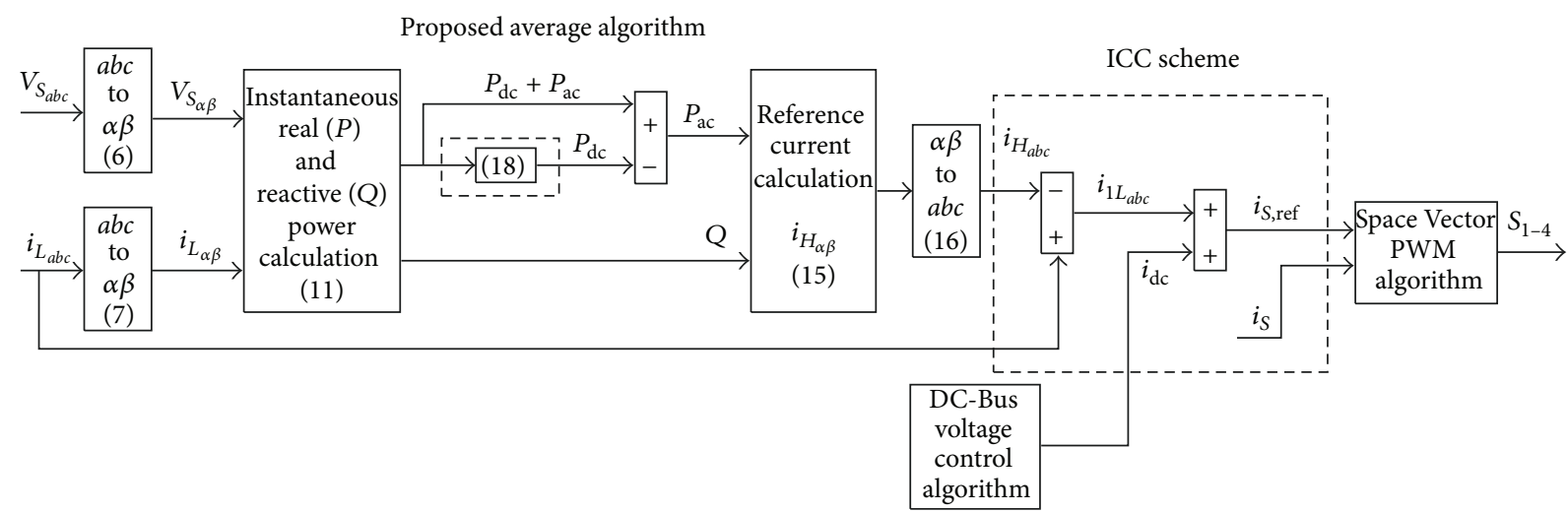

FIGURE 4: The proposed Enhanced PQ with average algorithm operating with ICC scheme.

However, under the influences of nonlinear loads, the actual $P$ and $Q$ values are polluted by additional disturbances resulting in the formation of new Instantaneous Power relationship given as

$$
\left[\begin{array}{l}
P \\
Q
\end{array}\right]=\left[\begin{array}{c}
P_{\mathrm{dc}}+P_{\mathrm{ac}} \\
Q_{\mathrm{dc}}+Q_{\mathrm{ac}}
\end{array}\right],
$$

where $P_{\mathrm{dc}}$ and $P_{\mathrm{ac}}$ represent the fundamental $(\mathrm{dc})$ and distorted (ac) components of instantaneous real power, respectively. Similar relation holds for reactive powers, $Q_{\mathrm{dc}}$ and $Q_{\mathrm{ac}}$.

For the purpose of harmonics extraction, only $P_{\mathrm{ac}}$ is required to generate the current harmonics $i_{H_{\alpha \beta}}$. The $P_{\mathrm{ac}}$ components are obtained by removing the $P_{\mathrm{dc}}$ component from the original $P$ value. This approach can be represented as follows:

$$
P_{\mathrm{ac}}=P-P_{\mathrm{dc}} .
$$

Previously, the fundamental component $P_{\mathrm{dc}}$ detection is mostly accomplished by using Butterworth-type tuned numerical LPF $[11,14,17,42]$. However, the tuning of cutoff frequency and the selection of filter's order are quite difficult tasks. Generally, LPF with higher cutoff frequency provides a fast dynamic response, but some unwanted components remain (as ripples) in the filtered signal while lower cutoff frequency provides a smoother filtered signal (less ripples) but slow dynamic response. On the other hand, a low order LPF provides fast dynamic response but poor filtering effect (more ripples). Meanwhile, high order LPF has a good filtering effect (less ripples), but it suffers from longer time delay $[13,42]$. Therefore, a good trade-off between cutoff frequency and order of filter is crucial for optimum performance, but this is a tough decision to be made.

From the literature, in order to achieve a balance between dynamic response and filtering performance, the best cutoff frequency is reported to be in the range of $5 \mathrm{~Hz}$ to $35 \mathrm{~Hz}[11,13$, 14], and meanwhile the order of filter is limited to the second order as the higher order filter imposes great computational burden to the controller $[13,17,42]$. However, no matter how good the trade-off has been done to the numerical LPF, it is still not a promising solution to achieve fast and smooth filtering performance.

Once the $P_{\mathrm{dc}}$ component is subtracted from the original $P$ value, (11) can be rewritten as

$$
\left[\begin{array}{c}
P_{\mathrm{ac}} \\
\mathrm{Q}
\end{array}\right]=\left[\begin{array}{cc}
v_{\alpha} & v_{\beta} \\
-v_{\beta} & v_{\alpha}
\end{array}\right]\left[\begin{array}{c}
i_{H_{\alpha}} \\
i_{H_{\beta}}
\end{array}\right],
$$

where $i_{H_{\alpha}}$ and $i_{H_{\beta}}$ represent the current harmonics components in $\alpha-\beta$ coordinates.

From (14), the inverse matrix is taken to generate the required current harmonics in $\alpha$ - $\beta$ coordinates and is expressed as follows:

$$
\left[\begin{array}{c}
i_{H_{\alpha}} \\
i_{H_{\beta}}
\end{array}\right]=\frac{1}{\operatorname{det}(P Q)}\left[\begin{array}{cc}
v_{\alpha} & -v_{\beta} \\
v_{\beta} & v_{\alpha}
\end{array}\right]\left[\begin{array}{c}
P_{\mathrm{ac}} \\
Q
\end{array}\right],
$$

where $\operatorname{det}(P Q)=v_{\alpha}^{2}+v_{\beta}^{2}$.

Inverse Clarke-transformation as shown in (16) is then performed to transform $i_{H_{\alpha \beta}}$ in $\alpha$ - $\beta$ coordinates back to threephase current harmonics $i_{H_{a b c}}$ which is then used to derive the required reference injection current $i_{\text {inj,ref }}$. Consider

$$
\left[\begin{array}{l}
i_{H_{a}} \\
i_{H_{b}} \\
i_{H_{c}}
\end{array}\right]=\sqrt{\frac{2}{3}}\left[\begin{array}{cc}
1 & 0 \\
-\frac{1}{2} & \frac{\sqrt{3}}{2} \\
-\frac{1}{2} & -\frac{\sqrt{3}}{2}
\end{array}\right]\left[\begin{array}{l}
i_{H_{\alpha}} \\
i_{H_{\beta}}
\end{array}\right] .
$$

The reference injection current is derived based on the following equation:

$$
i_{\text {inj,ref }}=i_{H_{a b c}}+i_{\mathrm{dc}} .
$$

The nonsinusoidal $i_{\text {inj,ref }}$ forces the subsequent switching signals $S_{1-4}$ to be generated based on DCC scheme which operates by requiring the measurement of actual injection current $i_{\text {inj. }}$.

3.2. Proposed Modifications. Based on Figure 4, it is clear that two major modifications are applied to the conventional 
$P Q$ Theory algorithm to implement the Enhanced $P Q$ with average algorithm.

The first modification is implemented aiming at overcoming two major drawbacks of tuned numerical LPF which includes tedious tuning workload and significant delay in $P_{\mathrm{dc}}$ detection. For this purpose, a mathematical average algorithm is proposed which replaces the tuned numerical LPF in $P_{\mathrm{dc}}$ detection. The proposed mathematical average algorithm is given as

$$
P_{\mathrm{dc}}=P_{\text {average }}=\frac{1}{T} \int_{0}^{T} P d t,
$$

where $P_{\text {average }}$ is the average value of $P$ and $T$ is the period of the signal.

The mathematical average algorithm eliminates the need of filtering, thus removing the tuning workload as well as the possibility of inaccurate and inefficient $P_{\mathrm{dc}}$ detection due to improper tuning.

Next, the second modification is implemented aiming at solving the switching ripples problems, existing in source current which cannot be eliminated through DCC based operation. For this purpose, $P Q$ Theory algorithm that suits ICC based operation is proposed. In order to realize this modification, the characteristic of the generated reference current needs to be changed. Instead of deriving the reference current from $i_{H_{a b c}}$, the proposed algorithm makes it possible to derive the reference current from fundamental active current $i_{1 L_{a b c}}$.

The fundamental active current $i_{1 L_{a b c}}$ is made available by modifying the output of $i_{H_{a b c}}$ generated from the conventional $P Q$ Theory algorithm through an additional mathematical expression given as

$$
i_{1 L_{a b c}}=i_{L_{a b c}}-i_{H_{a b c}}
$$

where $i_{L_{a b c}}$ is the load current and $i_{H_{a b c}}$ is the current harmonics that resulted from (16).

The reference source current $i_{S \text {,ref }}$ is now derived based on (3). The sinusoidal $i_{S \text {, ref }}$ enables the subsequent switching signals $S_{1-4}$ to be generated based on the measurement of $i_{S}$ instead of $i_{\text {inj. }}$. In other words, it changes the DCC based operation to ICC based operation. In contrast to DCC based operation, ICC based operation which possesses the exact information on switching ripples, existing in the source current, eliminates any unnecessary problem caused by switching activities of SAPF.

Therefore, operating under ICC scheme is capable of ensuring the current harmonics to efficiently be mitigated, resulting in lower THD value of source current.

\section{Simulation Results}

The proposed three-phase three-level NPC inverter-based SAPF utilizing the Enhanced $P Q$ with average algorithm as the proposed harmonics extraction algorithm is tested and evaluated in MATLAB/Simulink. Simulation work is conducted under both steady and dynamic state conditions which involve two types of nonlinear loads. The first nonlinear load is constructed using a three-phase uncontrolled
TABLE 1: The proposed parameters for SAPF.

\begin{tabular}{lc}
\hline Parameter & Value \\
\hline Voltage source & $400 \mathrm{Vrms}, 50 \mathrm{~Hz}$ \\
DC-Bus capacitor & $3300 \mu \mathrm{F}$ (each) \\
DC-Bus reference voltage & $880 \mathrm{~V}$ \\
Limiting inductor & $5 \mathrm{mH}$ \\
Switching frequency & $25 \mathrm{kHz}$ \\
\hline
\end{tabular}

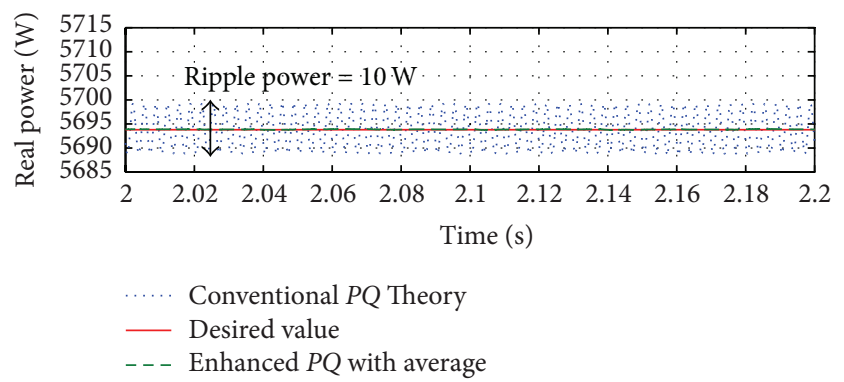

FIGURE 5: Fundamental real power $P_{\mathrm{dc}}$ detected by each harmonics extraction algorithm for capacitive load.

bridge rectifier feeding a $50 \Omega$ resistor and $2200 \mu \mathrm{F}$ capacitor connected in parallel (capacitive), while the second nonlinear load is developed using similar rectifier feeding a series connected $30 \Omega$ resistor and $50 \mathrm{mH}$ inductor (inductive). Furthermore, the conventional $P Q$ Theory algorithm is also tested for comparison purpose. The details of the proposed parameters are summarized in Table 1.

Under steady state condition, three key parameters are used in analyzing the performance of each harmonics extraction algorithm which includes percentage of ripple power, THD value, and power factor. The percentage of ripple power $\% \mathrm{RP}$ is a newly proposed parameter and is defined as the ratio of peak-to-peak fundamental real power $P_{\mathrm{dc}, \mathrm{pp}}$ to the desired fundamental real power $P_{\mathrm{dc} \text {,desired }}$ as given in the following equation:

$$
\% \mathrm{RP}=\frac{P_{\mathrm{dc}, \mathrm{pp}}}{P_{\mathrm{dc}, \text { desired }}} \times 100 .
$$

Meanwhile, under dynamic state condition, the performance parameters involved are undershoot, overshoot, and response time. For this analysis, two dynamic state conditions are created by changing the nonlinear load from capacitive to inductive and from inductive to capacitive loads, respectively.

4.1. Steady State Condition. Figures 5 and 6 show the performance of each harmonics extraction algorithm in detecting the fundamental real power $P_{\mathrm{dc}}$ for capacitive and inductive loads, respectively. Both algorithms detect the fundamental real power well, but they differ in terms of percentage of ripple power. The proposed Enhanced $P Q$ with average algorithm provides accurate fundamental real power detection without any ripple for both nonlinear loads. In contrast, the conventional PQ Theory algorithm produces fundamental 


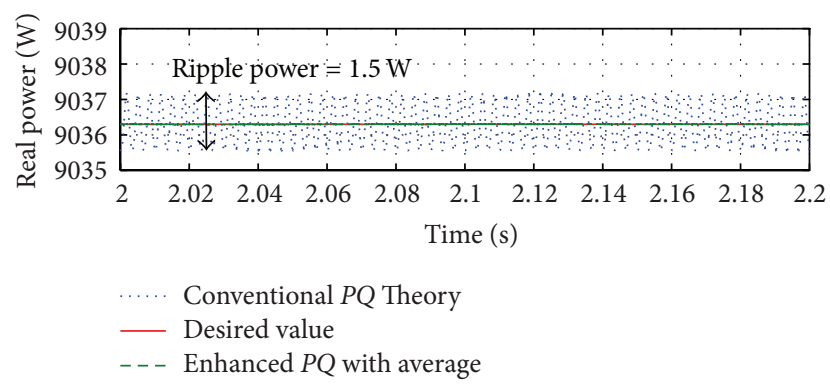

FIGURE 6: Fundamental real power $P_{\mathrm{dc}}$ detected by each harmonics extraction algorithm for inductive load.
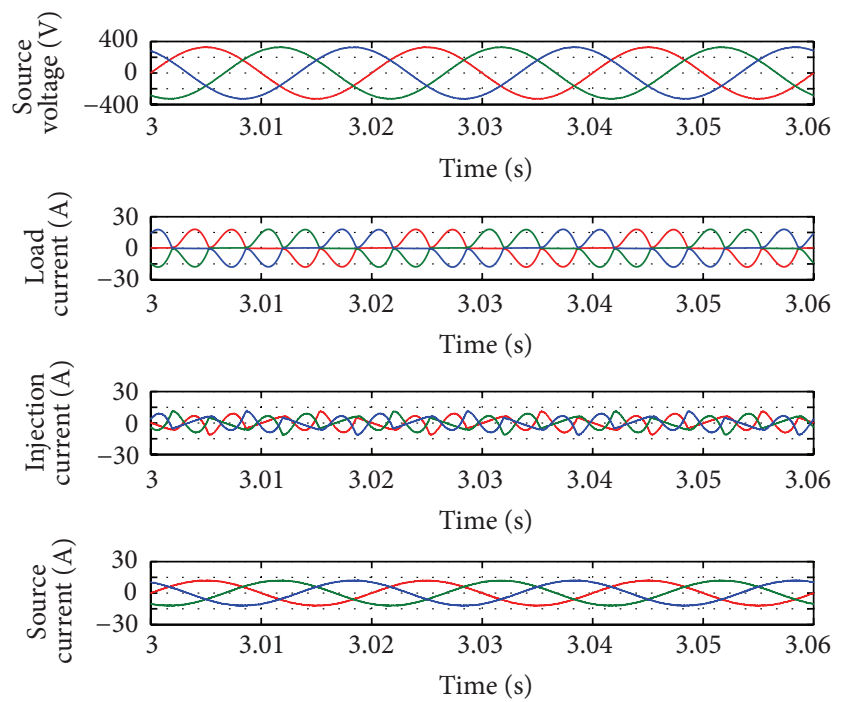

$$
\begin{aligned}
& \text { Phase A } \\
& \text { — Phase B } \\
& \text { — Phase C }
\end{aligned}
$$

FIGURE 7: Three-phase simulation waveforms for source voltage $v_{S}$, load current $i_{L}$, injection current $i_{\text {inj }}$, and source current $i_{S}$ resulted from the proposed Enhanced $P Q$ with average algorithm for capacitive load.

real power with ripple powers of $10 \mathrm{~W}(\% \mathrm{RP}=0.17 \%)$ and $1.5 \mathrm{~W}(\% \mathrm{RP}=0.02 \%)$ for capacitive and inductive loads, respectively.

The findings prove that the proposed mathematical average algorithm is able to detect the desired fundamental real power component with higher accuracy compared to the tuned numerical LPF.

On the other hand, Figures 7 and 8 show the three-phase waveforms of source voltage $v_{S}$, load current $i_{L}$, injection current $i_{\text {inj, }}$, and source current $i_{S}$ that resulted from the proposed Enhanced $P Q$ with average algorithm for capacitive and inductive loads, respectively. Meanwhile, the THD values of source current $i_{S}$ mitigated by SAPF utilizing each harmonics extraction algorithm are summarized in Table 2.

Both algorithms successfully control the SAPF to remove the generated current harmonics resulting in THD value below 5\% which complies with the limit set by IEEE Standard 519-2014 [30]. However, the proposed Enhanced PQ with
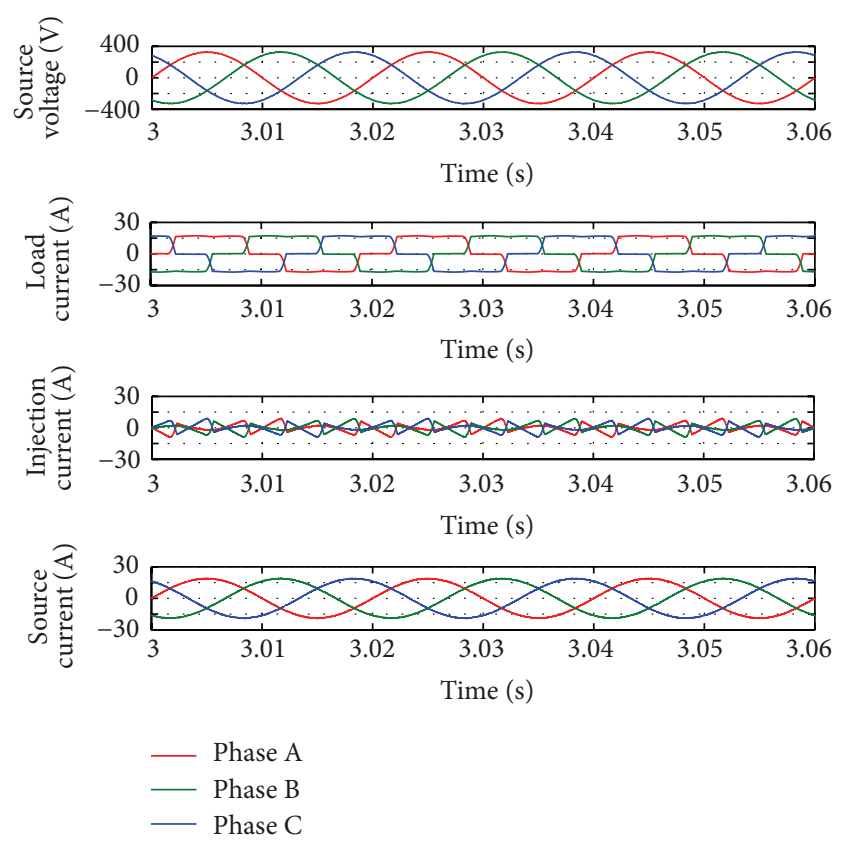

FIGURE 8: Three-phase simulation waveforms for source voltage $v_{S}$, load current $i_{L}$, injection current $i_{\text {inj }}$, and source current $i_{S}$ resulted from the proposed Enhanced $P Q$ with average algorithm for inductive load.

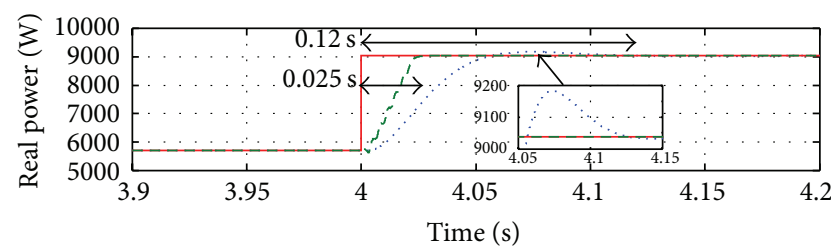

$\ldots$. Conventional $P Q$ Theory
- Desired value
--- Enhanced $P Q$ with average

FIGURE 9: Fundamental real power $P_{\mathrm{dc}}$ detected by each harmonics extraction algorithm for dynamic state condition of capacitive to inductive load.

average algorithm shows superior performance in reducing the switching ripples existing in the source current $i_{S}$ by achieving a lower THD value for both capacitive and inductive loads compared to the conventional PQ Theory algorithm. Furthermore, the mitigated source current $i_{S}$ seems to work in phase with the source voltage $v_{S}$ for both nonlinear loads which lead to almost unity power factor.

4.2. Dynamic State Condition. Figures 9 and 10 show the dynamic behaviour of each harmonics extraction algorithm in detecting the fundamental real power $P_{\mathrm{dc}}$ for dynamic state conditions of capacitive to inductive and inductive to capacitive loads, respectively.

For capacitive to inductive load, the proposed Enhanced $P Q$ with average algorithm shows the best performance with response time of $0.025 \mathrm{~s}$ and no overshoot. Meanwhile, the 
TABLE 2: THDs of mitigated source current obtained from each harmonics extraction algorithm for capacitive (RC) and inductive (RL) loads.

\begin{tabular}{|c|c|c|c|c|c|c|}
\hline \multirow{3}{*}{ Harmonics extraction algorithm } & \multicolumn{6}{|c|}{ Total Harmonic Distortion, THD (\%) } \\
\hline & \multicolumn{2}{|c|}{ Phase A } & \multicolumn{2}{|c|}{ Phase B } & \multicolumn{2}{|c|}{ Phase C } \\
\hline & $\mathrm{RC}$ & RL & $\mathrm{RC}$ & RL & $\mathrm{RC}$ & RL \\
\hline \multicolumn{7}{|c|}{ Before connecting SAPF } \\
\hline N/A & 62.30 & 26.07 & 62.30 & 26.07 & 62.30 & 26.07 \\
\hline \multicolumn{7}{|c|}{ After connecting SAPF } \\
\hline Conventional PQ Theory & 2.10 & 1.24 & 2.08 & 1.25 & 2.12 & 1.24 \\
\hline Enhanced $P Q$ with average & 1.56 & 1.01 & 1.52 & 0.96 & 1.60 & 1.02 \\
\hline
\end{tabular}

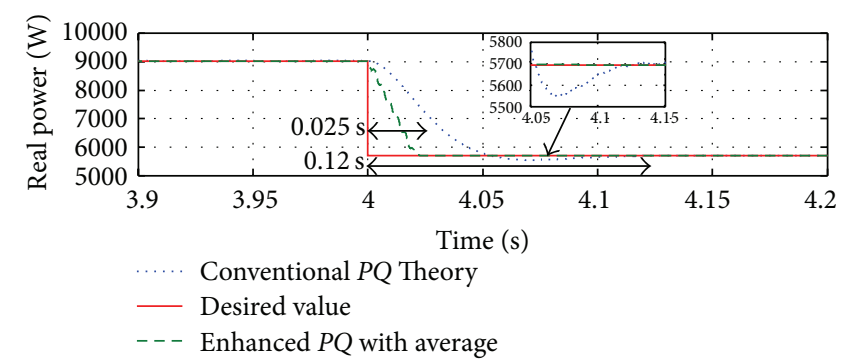

FIGURE 10: Fundamental real power $P_{\mathrm{dc}}$ detected by each harmonics extraction algorithm for dynamic state condition of inductive to capacitive load.

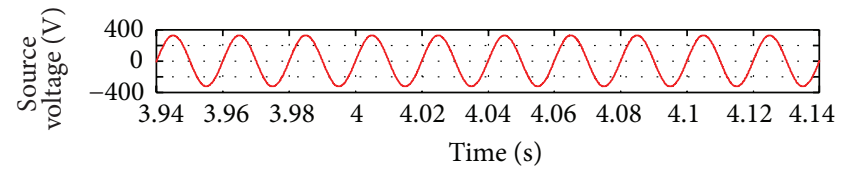

(a)

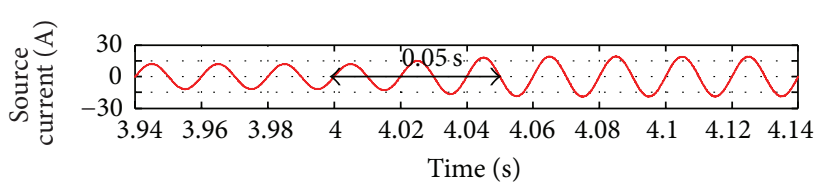

(c)

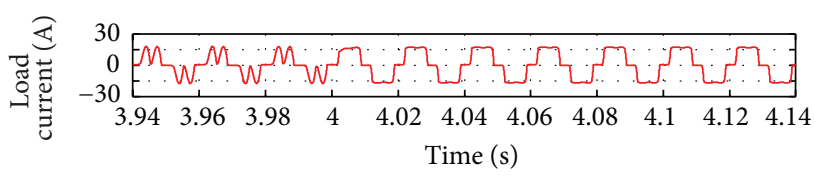

(b)

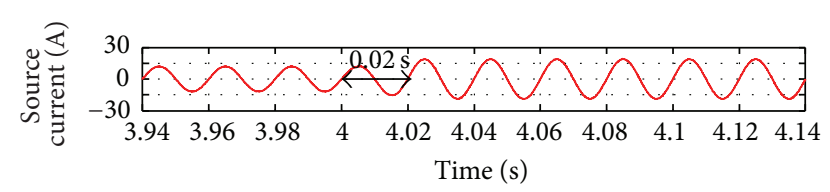

(d)

FIGURE 11: Phase A simulation waveforms for dynamic state condition of capacitive to inductive load for (a) source voltage $v_{S}$, (b) load current $i_{L}$, and (c) source current $i_{S}$ resulted from conventional PQ Theory algorithm, and (d) source current $i_{S}$ resulted from Enhanced $P Q$ with average algorithm.

conventional $P Q$ Theory algorithm performs poorly with response time of $0.12 \mathrm{~s}$ and high overshoot of $150 \mathrm{~W}$.

Similarly, for inductive to capacitive load, the proposed Enhanced $P Q$ with average algorithm also shows the best performance with response time of $0.025 \mathrm{~s}$ and no undershoot. Meanwhile, the conventional PQ Theory algorithm performs poorly with response time of $0.12 \mathrm{~s}$ and high undershoot of $150 \mathrm{~W}$.

The findings prove that, in terms of fundamental real power detection, the proposed algorithm shows superior dynamic performance by achieving a response time 4.8 times faster than the conventional algorithm.

On the other hand, Figures 11 and 12 show the dynamic behaviour of each harmonics extraction algorithm in current harmonics mitigation for dynamic state conditions of capacitive to inductive and inductive to capacitive loads, respectively.

For both dynamic state conditions, the proposed Enhanced $P Q$ with average algorithm shows the best performance with response time of $0.02 \mathrm{~s}$. Meanwhile, the conventional $P Q$ Theory algorithm performs poorly with response time of $0.05 \mathrm{~s}$.

Thus, in terms of current harmonics mitigation, SAPF with the proposed algorithm shows superior dynamic performance by achieving a response time 2.5 times faster than the conventional algorithm.

Furthermore, in order to study the effectiveness of the proposed SAPF, performance evaluation in terms of DC-Bus voltage control and neutral point voltage deviation control is also conducted. 


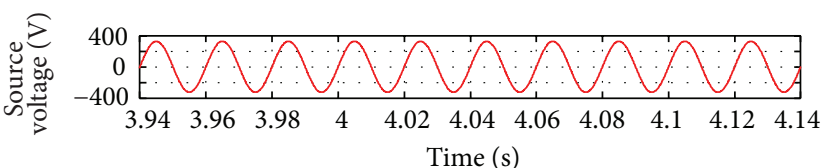

(a)

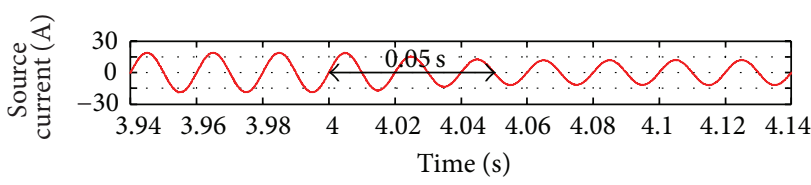

(c)

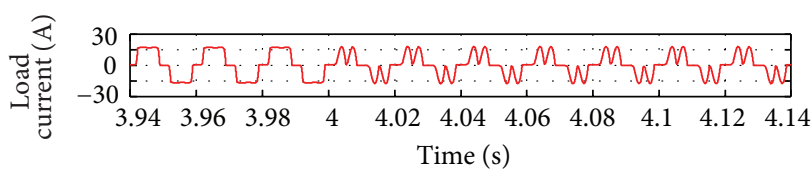

(b)

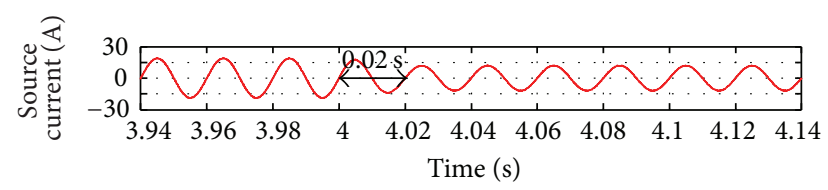

(d)

FIGURE 12: Phase A simulation waveforms for dynamic state condition of inductive to capacitive load for (a) source voltage $v_{S}$, (b) load current $i_{L}$, and (c) source current $i_{S}$ resulted from conventional PQ Theory algorithm, and (d) source current $i_{S}$ resulted from Enhanced $P Q$ with average algorithm.

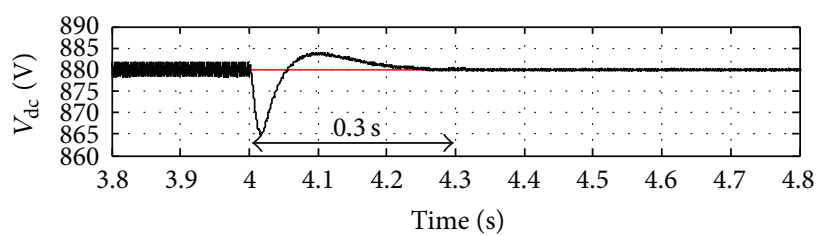

_ Desired value

- Overall DC-Bus voltage, $V_{\mathrm{dc}}$

(a)

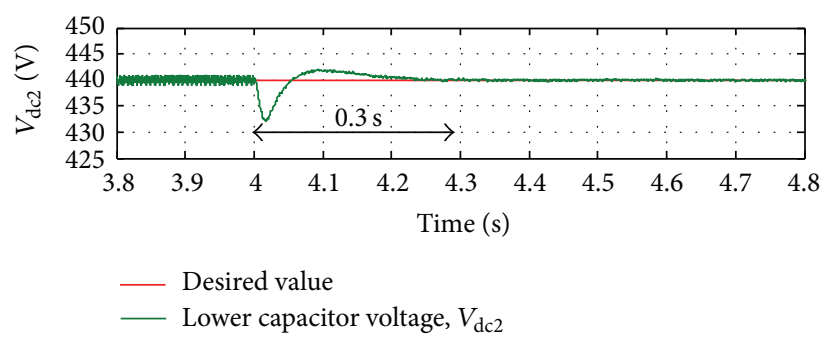

(c)

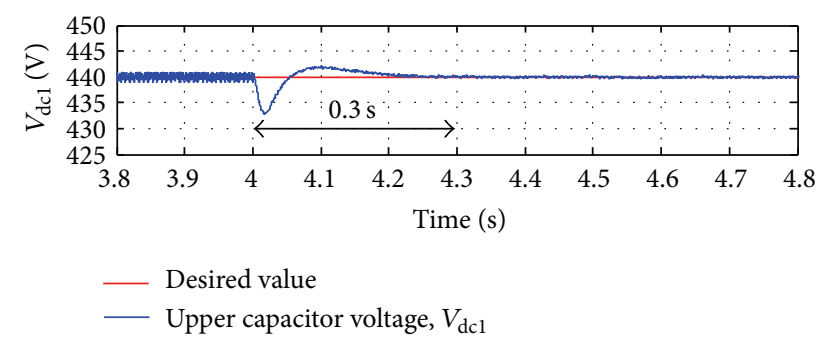

(b)

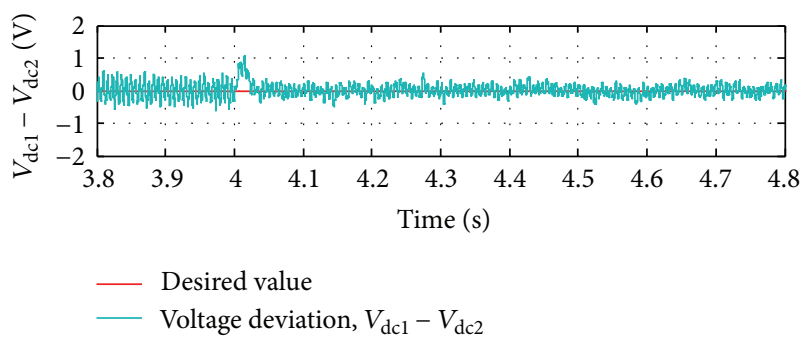

(d)

FIGURE 13: Simulation waveforms of (a) overall DC-Bus voltage $V_{\mathrm{dc}}$, (b) upper capacitor voltage $V_{\mathrm{dc} 1}$, (c) lower capacitor voltage $V_{\mathrm{dc} 2}$, and (d) neutral point voltage deviation $\left(V_{\mathrm{dc} 1}-V_{\mathrm{dc} 2}\right)$, for dynamic state condition of capacitive to inductive load.

Figures 13 and 14 show the simulation results obtained for the overall DC-Bus voltage $V_{\mathrm{dc}}$, the split capacitor voltages $\left(V_{\mathrm{dc} 1}\right.$ and $\left.V_{\mathrm{dc} 2}\right)$, and neutral point voltage deviation $\left(V_{\mathrm{dc} 1}-\right.$ $\left.V_{\mathrm{dc} 2}\right)$ for dynamic state conditions of capacitive to inductive and inductive to capacitive loads, respectively.

The results show that all the DC-Bus voltages $\left(V_{\mathrm{dc}}, V_{\mathrm{dc} 1}\right.$, and $V_{\mathrm{dc} 2}$ ) of the proposed SAPF are properly controlled at desired value with response time of $0.3 \mathrm{~s}$ for both dynamic state conditions. Moreover, voltages across each split capacitor $\left(V_{\mathrm{dc1}}\right.$ and $\left.V_{\mathrm{dc2}}\right)$ are successfully maintained as half of the overall DC-Bus voltage $V_{\mathrm{dc}}$ with the minimal neutral point voltage deviation. The findings prove the effectiveness of the DC-Bus voltage control algorithm and neutral point voltage control algorithm applied in the proposed SAPF.

From all the simulation results obtained in both steady and dynamic state conditions, the improvements achieved by the proposed Enhanced $P Q$ with average algorithm have revealed significant roles of applying the mathematical average algorithm and modifying the characteristic of generated reference current to suit ICC based operation. The implementation of the proposed algorithm has significantly improved the performances of the proposed SAPF.

By providing accurate and fast fundamental real power detection together with the ability to generate sinusoidal reference current, significant improvements in terms of THD value and dynamic response in current harmonics mitigation are achieved. The THD value recorded by using the proposed algorithm is in better range that is within $0.96 \%$ to $1.60 \%$ as compared to the conventional algorithm which performs within the range of $1.24 \%$ to $2.12 \%$. Most importantly, by using the proposed algorithm, the response time of two and half cycles $(0.05 \mathrm{~s})$ in harmonics mitigation which is achieved previously by using the conventional algorithm is now significantly reduced to one cycle $(0.02 \mathrm{~s})$. 


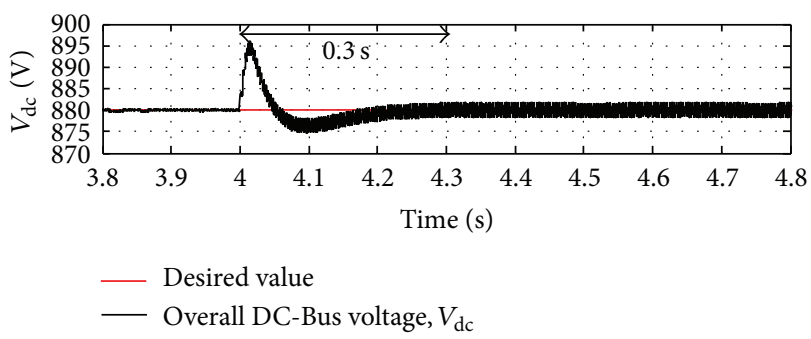

(a)

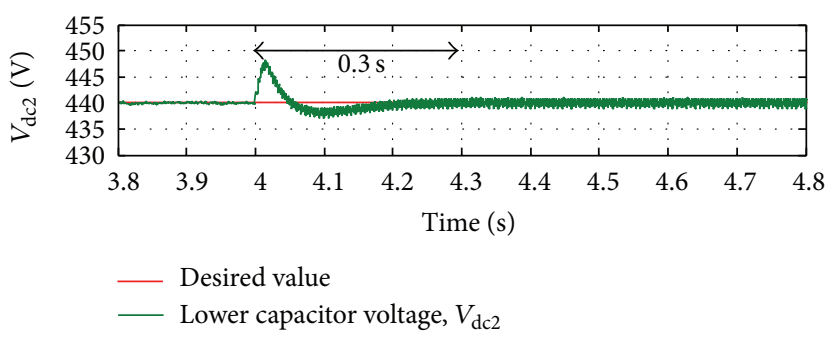

(c)

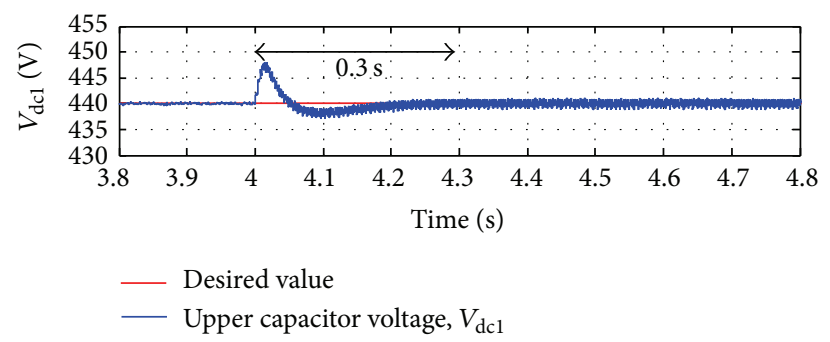

(b)

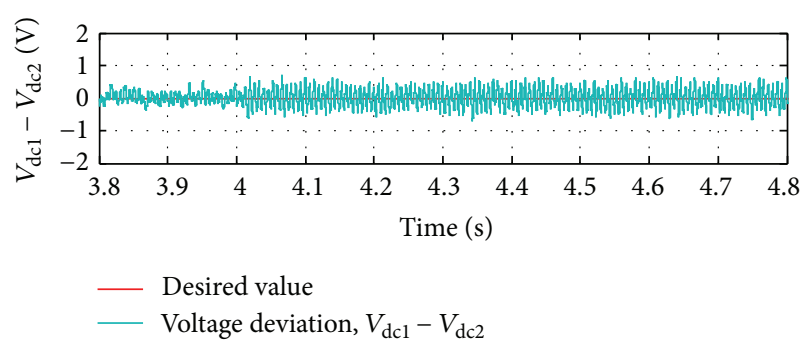

(d)

FIGURE 14: Simulation waveforms of (a) overall DC-Bus voltage $V_{\mathrm{dc}}$, (b) upper capacitor voltage $V_{\mathrm{dc1}}$, (c) lower capacitor voltage $V_{\mathrm{dc} 2}$, and (d) neutral point voltage deviation $\left(V_{\mathrm{dc} 1}-V_{\mathrm{dc} 2}\right)$, for dynamic state condition of inductive to capacitive load.

In addition, the successful control of all the DC-Bus voltages at desired value together with minimal neutral point voltage deviation has further verified the design concept and the effectiveness of the proposed SAPF in current harmonics mitigation.

\section{Conclusion}

This paper has presented an Enhanced PQ Theory algorithm which is applicable in ICC based SAPF. The following points summarize the major contributions of this work.

(1) Mathematical average algorithm is proposed to replace sluggish numerical filter in fundamental component detection. It provides accurate and fast detection ability and at the same time eliminates the needs of dull and tedious tuning workload.

(2) A mathematical current relationship is added to the proposed algorithm which provides the ability to generate sinusoidal reference current. By using this approach, the $P Q$ Theory algorithm can now be implemented in ICC based SAPF which was previously only applicable in DCC based SAPF. Consequently, such technique indirectly improves the THD value of the mitigated source current through the elimination of switching ripples.

The analysis in both steady and dynamic state conditions is conducted to evaluate the performance of the proposed algorithm. Moreover, comparative evaluation with the conventional algorithm is also conducted to verify the improvement achieved by the proposed algorithm. In steady state condition, the proposed algorithm is not only able to control the SAPF in mitigating the current harmonics with lower THD value for both capacitive and inductive nonlinear loads, but also able to eliminate ripples that remained in the detected fundamental component. On the other hand, significant improvement can be observed during dynamic state conditions where the proposed algorithm has successfully performed with fast response time, no undershoot, and no overshoot.

The comprehensive findings of this work clearly show the advantages of the proposed Enhanced $P Q$ with average algorithm over the conventional $P Q$ Theory algorithm especially in dealing with dynamic state conditions.

\section{Competing Interests}

The authors declare that there is no conflict of interests regarding the publication of this paper.

\section{References}

[1] S. Khalid and B. Dwivedi, "Power quality issues, problems, standards and their effects in industry with corrective means," International Journal of Advances in Engineering \& Technology, vol. 1, no. 1, pp. 1-11, 2011.

[2] M. K. Soni and N. Soni, "Review of causes and effect of harmonics on power system," International Journal of Science, Engineering and Technology Research, vol. 3, no. 2, pp. 214-220, 2014.

[3] R. D. Henderson and P. J. Rose, "Harmonics: the effects on power quality and transformers," IEEE Transactions on Industry Applications, vol. 30, no. 3, pp. 528-532, 1994.

[4] B. Singh, K. Al-Haddad, and A. Chandra, "A review of active filters for power quality improvement," IEEE Transactions on Industrial Electronics, vol. 46, no. 5, pp. 960-971, 1999.

[5] H. Akagi, "Active harmonic filters," Proceedings of the IEEE, vol. 93, no. 12, pp. 2128-2141, 2005. 
[6] J. Rodríguez, J.-S. Lai, and F. Z. Peng, "Multilevel inverters: a survey of topologies, controls, and applications," IEEE Transactions on Industrial Electronics, vol. 49, no. 4, pp. 724-738, 2002.

[7] D. Soto and T. C. Green, "A comparison of high-power converter topologies for the implementation of FACTS controllers," IEEE Transactions on Industrial Electronics, vol. 49, no. 5, pp. 1072-1080, 2002.

[8] A. M. Massoud, S. J. Finney, A. J. Cruden, and B. W. Williams, "Three-phase, three-wire, five-level cascaded shunt active filter for power conditioning, using two different space vector modulation techniques," IEEE Transactions on Power Delivery, vol. 22, no. 4, pp. 2349-2361, 2007.

[9] C. Salim and B. M. Toufik, "Three-level (NPC) shunt active power filter performances based on fuzzy controller for harmonic currents compensation under non-ideal voltage conditions," International Journal on Electrical Engineering and Informatics, vol. 6, no. 2, pp. 342-358, 2014.

[10] A. Bhattacharya and C. Chakraborty, "A shunt active power filter with enhanced performance using ANN-based predictive and adaptive controllers," IEEE Transactions on Industrial Electronics, vol. 58, no. 2, pp. 421-428, 2011.

[11] N. Eskandarian, Y. A. Beromi, and S. Farhangi, "Improvement of dynamic behavior of shunt active power filter using fuzzy instantaneous power theory," Journal of Power Electronics, vol. 14, no. 6, pp. 1303-1313, 2014.

[12] A. Pigazo, V. M. Moreno, and E. J. Estébanez, "A recursive park transformation to improve the performance of synchronous reference frame controllers in shunt active power filters," IEEE Transactions on Power Electronics, vol. 24, no. 9, pp. 2065-2075, 2009.

[13] M. Monfared, S. Golestan, and J. M. Guerrero, "A new synchronous reference frame-based method for single-phase shunt active power filters," Journal of Power Electronics, vol. 13, no. 4, pp. 692-700, 2013.

[14] M. K. Syed and B. S. Ram, "Instantaneous power theory based active power filter: a MATLAB/Simulink approach," Journal of Theoretical and Applied Information Technology, vol. 4, no. 6, pp. 536-541, 2008.

[15] A. Hoseinpour and R. Ghazi, "Modified PWM technique for harmonic reduction," ISRN Electronics, vol. 2012, Article ID 917897, 8 pages, 2012.

[16] A. O. Montes and G. Ramos, "Instantaneous p-q theory for harmonic compensation via shunt active power filter," in Proceedings of the 1st Workshop on Power Electronics and Power Quality Applications (PEPQA '13), pp. 1-4, IEEE, Bogota, Colombia, July 2013.

[17] S. S. Wamane, J. R. Baviskar, and S. R. Wagh, "A comparative study on compensating current generation algorithms for shunt active filter under non-linear load conditions," International Journal of Scientific and Research Publications, vol. 3, no. 6, pp. 1-6, 2013.

[18] M. Popescu, A. Bitoleanu, and V. Suru, "A DSP-based Implementation of the $\mathrm{p}$ - $\mathrm{q}$ theory in active power filtering under nonideal voltage conditions," IEEE Transactions on Industrial Informatics, vol. 9, no. 2, pp. 880-889, 2013.

[19] S. Sujitjorn, K.-L. Areerak, and T. Kulworawanichpong, "The DQ axis with fourier (DQF) method for harmonic identification," IEEE Transactions on Power Delivery, vol. 22, no. 1, pp. 737-739, 2007.

[20] O. Vodyakho and C. C. Mi, "Three-level inverter-based shunt active power filter in three-phase three-wire and four-wire systems," IEEE Transactions on Power Electronics, vol. 24, no. 5, pp. 1350-1363, 2009.

[21] C. L. Chen, C. E. Lin, and C. L. Huang, "Reactive and harmonic current compensation for unbalanced three-phase systems using the synchronous detection method," Electric Power Systems Research, vol. 26, no. 3, pp. 163-170, 1993.

[22] G. Bhuvaneswari, M. G. Nair, and S. Kumar Reddy, "Comparison of synchronous detection and I. $\operatorname{Cos} \varphi$ shunt active filtering algorithms," in Proceedings of the International Conference on Power Electronics, Drives and Energy Systems (PEDES '06), pp. 1-5, New Delhi, India, December 2006.

[23] M. Forghani and S. Afsharnia, "Online wavelet transform-based control strategy for UPQC control system," IEEE Transactions on Power Delivery, vol. 22, no. 1, pp. 481-491, 2007.

[24] M. A. M. Radzi and N. A. Rahim, "Neural network and bandless hysteresis approach to control switched capacitor active power filter for reduction of harmonics," IEEE Transactions on Industrial Electronics, vol. 56, no. 5, pp. 1477-1484, 2009.

[25] B. Singh, V. Verma, and J. Solanki, "Neural network-based selective compensation of current quality problems in distribution system," IEEE Transactions on Industrial Electronics, vol. 54, no. 1, pp. 53-60, 2007.

[26] J. Fei, T. Li, F. Wang, and W. Juan, "A novel sliding mode control technique for indirect current controlled active power filter," Mathematical Problems in Engineering, vol. 2012, Article ID 549782, 18 pages, 2012.

[27] M. Adel, S. Zaid, and O. Mahgoub, "Improved active power filter performance based on an indirect current control technique," Journal of Power Electronics, vol. 11, no. 6, pp. 931-937, 2011.

[28] B. N. Singh, A. Chandra, and K. Al-Haddad, "Performance comparison of two current control techniques applied to an active filter," in Proceedings of the International Conference on Harmonics Quality Power (ICHQP '98), vol. 1, pp. 133-138, Athens, Greece, October 1998.

[29] S. Rahmani, K. Al-Haddad, and H. Y. Kanaan, "Experimental design and simulation of a modified PWM with an indirect current control technique applied to a single-phase shunt active power filter," in Proceedings of the IEEE International Symposium on Industrial Electronics (ISIE '05), vol. 2, pp. 519-524, Dubrovnik, Croatia, June 2005.

[30] IEEE Standards Association, "IEEE recommended practice and requirement for harmonic control in electric power systems," IEEE Standard 519, Institute of Electrical and Electronics Engineers, Piscataway, NJ, USA, 2014.

[31] S. P. Diwan, H. P. Inamdar, and A. P. Vaidya, "Simulation studies of shunt passive harmonic filters: six pulse rectifier load power factor improvement and harmonic control," ACEEE International Journal on Electrical and Power Engineering, vol. 2, no. 1, pp. 1-6, 2011.

[32] J. H. Marks and T. C. Green, "Predictive transient-following control of shunt and series active power filters," IEEE Transactions on Power Electronics, vol. 17, no. 4, pp. 574-584, 2002.

[33] L. H. Tey, P. L. So, and Y. C. Chu, "Improvement of power quality using adaptive shunt active filter," IEEE Transactions on Power Delivery, vol. 20, no. 2, pp. 1558-1568, 2005.

[34] T. R. Deva and N. K. Nair, "ANN based control algorithm for harmonic elimination and power factor correction using shunt active filter," International Journal of Electrical and Power Engineering, vol. 1, no. 2, pp. 152-157, 2007.

[35] A. K. Gupta and A. M. Khambadkone, "A space vector PWM scheme for multilevel inverters based on two-level space vector 
PWM," IEEE Transactions on Industrial Electronics, vol. 53, no. 5, pp. 1631-1639, 2006.

[36] H. Hu, W. Yao, and Z. Lu, "Design and implementation of threelevel space vector PWM IP core for FPGAs," IEEE Transactions on Power Electronics, vol. 22, no. 6, pp. 2234-2244, 2007.

[37] J. Tlustý, J. Škramlík, J. Švec, and V. Valouch, "Analytical modeling and simulation of four-switch hybrid power filter working with sixfold switching symmetry," Mathematical Problems in Engineering, vol. 2012, Article ID 292178, 17 pages, 2012.

[38] K. H. Bhalodi and P. Agarwal, "Space vector modulation with DC-link voltage balancing control for three-level inverters," ACEEE International Journal on Communication, vol. 1, no. 1, pp. 14-18, 2010.

[39] Y.-H. Lee, B.-S. Suh, and D.-S. Hyun, "A novel PWM scheme for a three-level voltage source inverter with GTO thyristors," IEEE Transactions on Industry Applications, vol. 32, no. 2, pp. 260-268, 1996.

[40] D. Zhou and D. G. Rouaud, "Experimental comparisons of space vector neutral point balancing strategies for three-level topology," IEEE Transactions on Power Electronics, vol. 16, no. 6, pp. 872-879, 2001.

[41] H. Akagi, Y. Kanazawa, and A. Nabae, "Instantaneous reactive power compensators comprising switching devices without energy storage components," IEEE Transactions on Industry Applications, vol. IA-20, no. 3, pp. 625-630, 1984.

[42] C. H. Ng, K. Busawon, G. A. Putrus, and L. Ran, "Fastindividual-harmonic-extraction technique," IEE Proceedings on Generation, Transmission and Distribution, vol. 152, no. 4, pp. 556-562, 2005. 


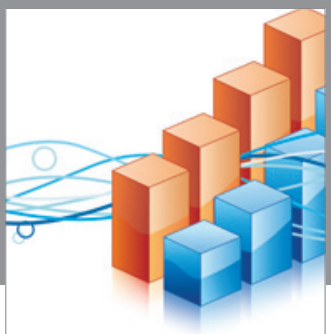

Advances in

Operations Research

vatem alat4

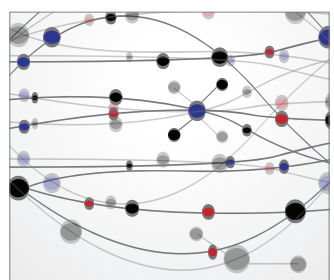

\section{The Scientific} World Journal
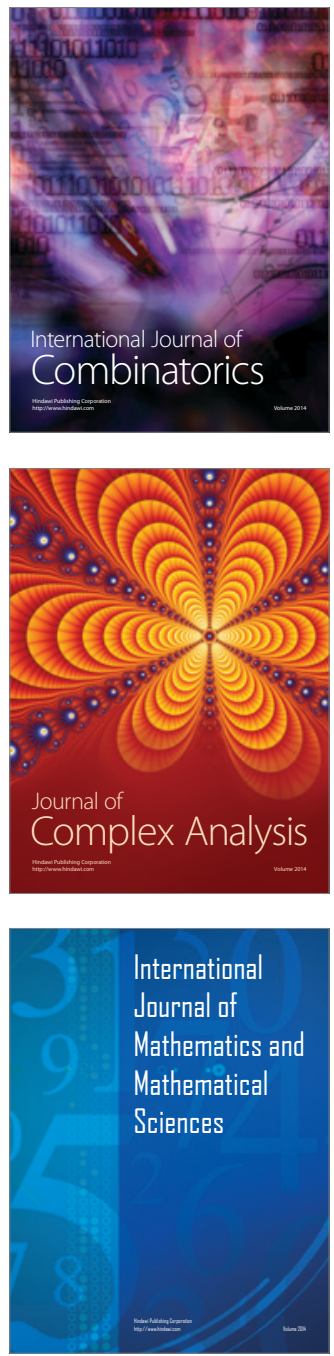
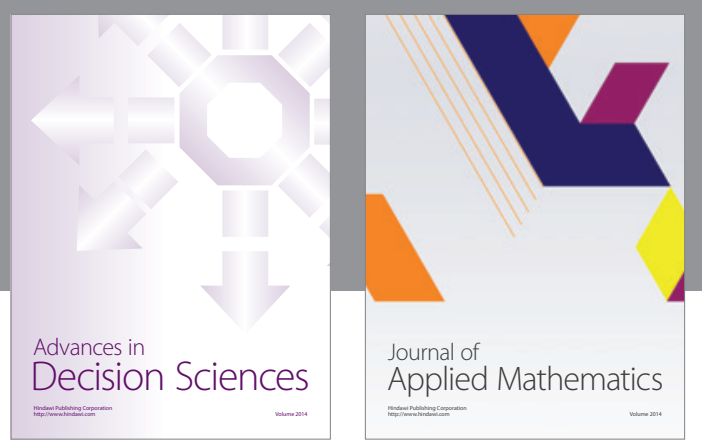

Algebra

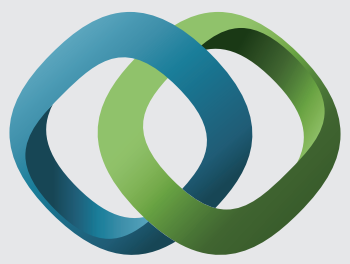

\section{Hindawi}

Submit your manuscripts at

http://www.hindawi.com
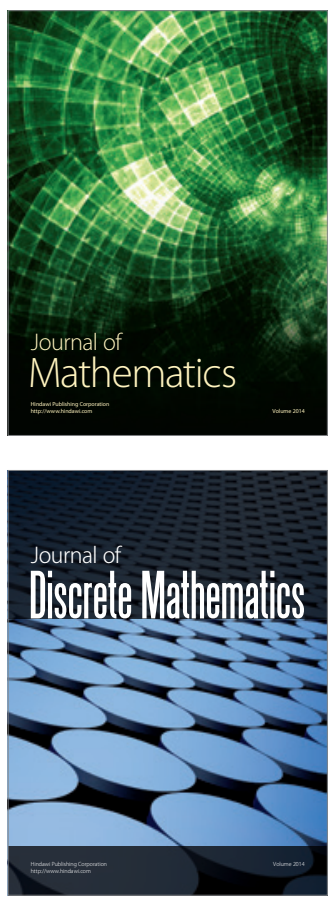

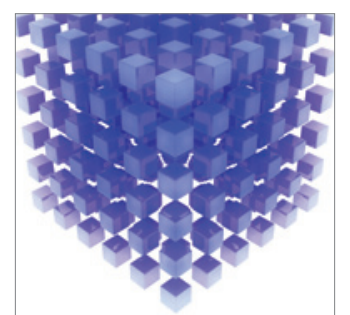

Mathematical Problems in Engineering
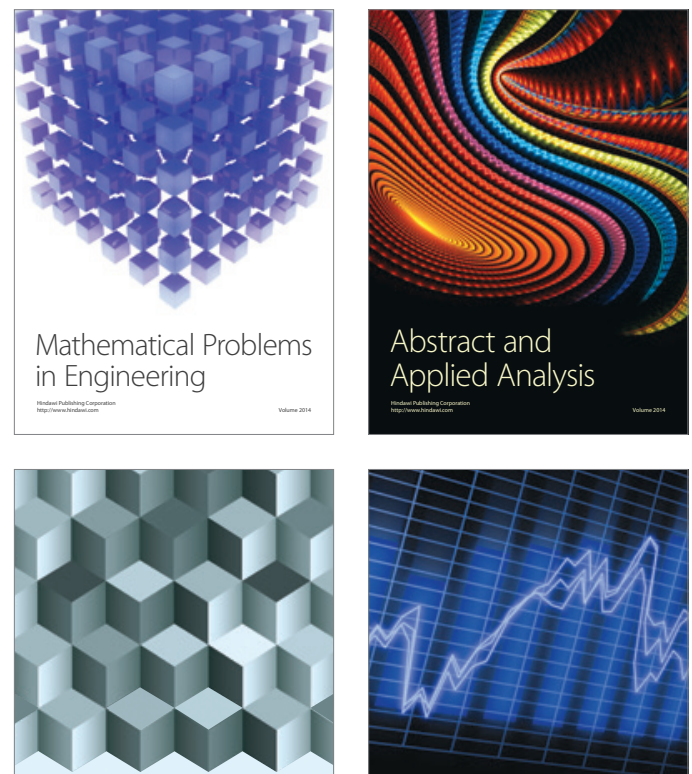

Journal of

Function Spaces

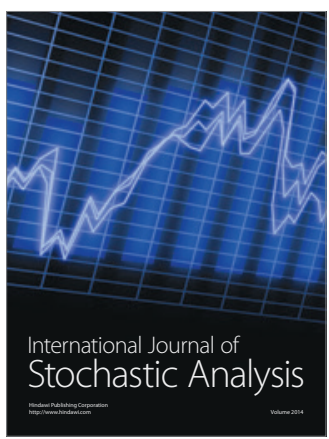

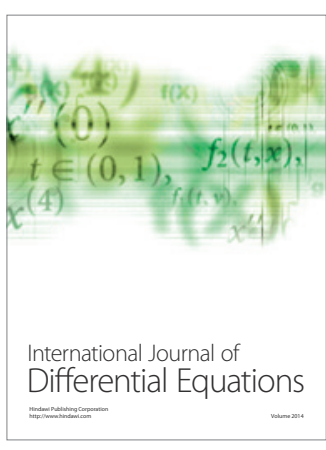
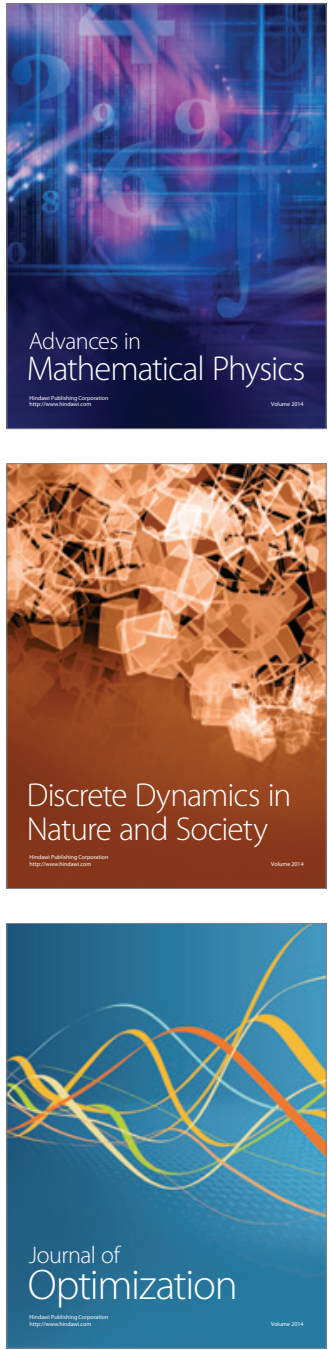